\title{
Socio-cognitive and personal characteristics of juvenile offenders: a field study
}

Características personales y sociocognitivas de los menores infractores: un estudio de campo.

Carmen Borrás ${ }^{1 *}$, Alfonso Palmer², Azucena Hernández ${ }^{3}$, and Joana Llobera ${ }^{3}$

\begin{abstract}
Adolescence is characterised by a higher prevalence of risk-taking and the challenging of social norms, which appears to bear a relationship to personal abilities and social-cognitive deficits. With the aim of understanding this relationship, a comparative study was undertaken with two groups of adolescents, one belonging to the standard population and one comprising young people who have been subject to correctional measures. In order to evaluate the variables involved, use was made of the Questionnaire for the Assessment of Psychopathology in Adolescence (Q-PAD). The results obtained show that both groups display significant differences in all the variables considered in the Questionnaire, with the exception of those relating to body dissatisfaction and family conflicts. Succinctly, it emerged that the juvenile offenders had emotional and interpersonal problems and were at risk of psychological disturbance. They demonstrated uncertainty about the future, liability to substance abuse, and issues of self-esteem. These results suggest the need for prevention and intervention programmes which specifically take into account these variables.
\end{abstract}

\section{Resumen}

La adolescencia constituye una etapa caracterizada por una mayor prevalencia de conductas de riesgo y antinormativas que se relacionan con competencias personales y sociocognitivas deficitarias. Al objeto de conocer dicha relación, se llevó a cabo un estudio comparativo con dos grupos de adolescentes - uno perteneciente a la población normal $(n=35)$ y el otro compuesto por jóvenes sujetos a medidas de reforma $(n=44)-$. Para la evaluación de las variables objeto de estudio se utilizó el Cuestionario para la Evaluación de Problemas en Adolescentes (Q-PAD). Los resultados obtenidos ponen de manifiesto que ambos grupos presentan diferencias significativas en todas las variables contempladas en el instrumento a excepción de las relativas a la insatisfacción corporal y a los conflictos familiares. Sucintamente, se encontró que los menores infractores presentan problemas emocionales, interpersonales, de riesgo psicosocial, incertidumbre sobre el futuro, abuso de sustancias y de autoestima. Los resultados sugieren la necesidad de programas de prevención e intervención que contemplen dichas variables de forma específica.

\section{Keywords}

Juvenile delinquency; psychological adjustment; conduct problems; social relations; self-esteem.

\section{Palabras Clave}

Delincuencia juvenil; ajuste psicológico; problemas de conducta; relaciones sociales; auto-estima.

${ }^{1}$ Area of Psychological Personality, Evaluation and Treatment. Faculty of Psychology in the University of the Balearic Islands.

${ }^{2}$ Area of Methodology of Behavioural Sciences. Faculty of Psychology in the University of the Balearic Islands, Spain.

${ }^{3}$ Equipo 25.2 Non-profit association for real, effective reinsertion. Palma de Mallorca, Spain.

*Corresponding author: carmen.borras@uib.es

Manuscript received 02-08-2016; revised 23-11-2016; accepted 18-12-2016.

\section{Introduction}

Adolescence is a stage that covers from the end of childhood to the onset of adulthood, which has led it to be understood as a transitory psychosociological period. This stage is charac- terised by a higher prevalence of risk-taking behaviour both inside and outside the law (Bringas, Rodríguez, Gutiérrez, \& Pérez, 2010) although, as Moral and Sirvent (2001) show, the existing literature reveals conflicting data in relation to the ve- 
racity and consistency of the conceptualisation of adolescence as a stage of conflicts.

During this stage of development, a large number of young people carry out antisocial behaviour, although they eventually end up adapting their behaviour to socially established norms. Nevertheless, the presence of aggressive behaviours in adolescence may point towards criminal behaviour in adulthood, as well as social maladjustment and interpersonal relationship problems (Andreu-Rodríguez, Peña-Fernández, \& Loza, 2016).Thus, adolescence is understood as a key period for the onset and maintenance of antisocial behaviour.

While aggressiveness can be understood as an adaptive response (Archer, 2009), violence would refer to aggressive behaviours that lack adaptive value, whose aim is to inflict harm. Violent conduct may reflect a dysfunction of the neural mechanisms involved in the control of this response (Anderson \& Bushman, 2002). In any event, and following Vassos, Collier, and Fazel (2104), aggression and violence would form part of the same behavioural continuum.

While cultural, environmental and social factors are understood to operate in the expression of violent conduct, in the same way personal and neuropsychological factors are seen to be involved, as revealed by the results found in relation to brain damage in the prefrontal cortex and orbitofrontal cortex during childhood and adolescence (Boes et al., 2011).

The repertoire of criminal conduct with the greatest social impact includes crimes against the person (homicides, injuries, and crimes against sexual freedom), although the most frequent unlawful conduct targets public health and violates property rights, notably violent robbery, robbery by intimidation, and vehicle theft (Arce, Fariña, \& Vázquez, 2011).

Should, during adolescence, these actions not be redirected towards social convention, they could entail the onset and development of criminal activities (Bringas, Rodríguez, López-Cepero, Pérez, \& Estrada, 2012) which will affect both the individual themselves and different areas of society in general (perceived satisfaction and well-being, public expenditure, amongst others).

Likewise, it has been observed that the percentage of primary juvenile offenders has risen considerably (Alves, Amando, \& Vilariño, 2013; Z., Woodhams, \& Cooke, 2014). For this reason, it is necessary to deal with recidivist behaviours as well as the increase in violence that accompanies them, since the greater the number of delinquent behaviours, the greater the likelihood of violent conduct at the end of adolescence and beginning of adulthood (Rutter, Giller, \& Hagell, 2000).

This highlights the importance of carrying out specific preventive and re-educational interventions aimed at breaking the criminal trajectory of juveniles. Alves et al. (2013) stress, in designing effective prevention and treatment programmes for these behaviours, it is especially relevant to know the risk factors for criminal conduct, although we consider it especially interesting to take into account possible protective factors and existing adaptive behaviours as well, even though they might take place within a criminal context.

From psychology, most intervention and prevention programmes with delinquents have been carried out under a cognitive-behavioural model, according to which delinquency is understood as a product of deficits of skills, cognitions and emotions (Peña \& Graña, 2006; Redondo, Martínez-Catena, \& Andrés-Pueyo, 2012); and these are, along with educational programmes, clearly more effective than the average of the ones developed from other perspectives (Redondo, SánchezMeca, \& Garrido, 2002).

According to some studies conducted, juveniles with a high risk of social deviance talk of negative behaviours, a desire for isolation, critical attitudes, and insecurity, which have comorbidity with future antisocial conduct. The inclusion of not only legal criteria in the conceptualisation of antisocial behaviour has the advantage of being able to adequately take into account both personal and social factors, thereby enabling the real problem to be addressed directly (Peña \& Graña, 2006), making it possible to make up for the shortcomings of the offenders that are assumed to be linked to their criminal activity (Redondo et al., 2002).

Nevertheless, it is important to point out that social misfits do not carry out socially and personally maladjusted behaviours continuously, but rather these behaviours are part of their natural repertoire of behaviours when it comes to resolving or coping with problematic social situations (Arce, Mohamed, Fariña, \& Seijo, 2010).

In short, as shown by Bringas, Rodríguez, and Herrero (2009), in the explanation of adaptive and maladaptive behaviours it is necessary to take into account both personal characteristics (hyperactivity, extraversion, responsibility, impulsiveness or thrill seeking) and social-cognitive variables - understood as the result of an individual's interaction with their environment, which includes expectations, information processing and problem-solving skills.

In the present paper, which is part of a broader study, an analysis is performed of some variables related to personal and social adjustment in a group of young people in custody - closed and semi-open regime - and in a group of young people belonging to the standard population, in order to find out the possible differences existing between both groups.

\section{Method}

\subsection{Participants}

The sample was made up of a counterbalanced group of 79 adolescents resident in Mallorca, belonging to two clearly differentiated groups: 44 adolescents ( 40 boys and 4 girls) subject to correctional measures in the Social-education Centre 'EsPinaret' in Mallorca (Spain), derived by the Juvenile Courts of the Balearic Islands between the months of December 2014 and February 2015. That is, this study group was made up of all the young inmates in the aforementioned Social-education Centre who were committed during this period. The age range of this group is 14 to 20 years, with a 
mean of 17.18 years $(S D=1.50)$.

The involuntary commitment of the components of this group was justified because of the commission of one or more crimes related to a risk of recidivism (M. J. López, Alba, \& Garrido, 2007).

Specifically, the total number of crimes committed by this group is $103,32 \%$ of which correspond to property crime; crimes against the person represent 20\%; multiple crimes, crimes against the Administration of Justice, and against sexual freedom, represent $12 \%, 11 \%$ and $10 \%$, respectively. $8 \%$ and $6 \%$ correspond to offences classed as crimes against freedom and collective security, respectively; and privacy crimes represent $1 \%$.

On the other hand, there was a group of 35 adolescents ( 32 boys and 3 girls) between 14 and 20 years old, with a mean age of 16.97 years $(S D=1.62)$ belonging to the standard population, whose participation was voluntary and who were selected in accordance with the sociodemographic characteristics of the group of juvenile offenders. The present study was favourably assessed by the Bioethics Committee of the University of the Balearic Islands (UIB).

\subsection{Instruments}

To assess the variables involved, the Spanish adaptation of the Questionnaire for the Assessment of Psychopathology in Adolescence (Q-PAD) (Sica, Chiri, Favilli, \& Marchetti, 2016) was used, the aim of which is the comprehensive assessment of adolescents. This instrument consists of nine scales. Eight of these: anxiety (ANS), depression (DEP), interpersonal conflicts $(\mathrm{CON})$, family problems (FAM), body dissatisfaction (INS), uncertainty about the future (INC), substance abuse (ABU) and psychosocial risk (RPS) take into account a wide range of personal and social-cognitive variables that can constitute risk factors. Thereby, the Q-PAD provides a measure of important domains of psychopathological interest described in the scientific literature regarding adolescents, whilst also making it possible to obtain an index of risk of adjustment or psychosocial risk of the adolescents assessed, which can provide relevant information as to the type of intervention necessary (Sica et al., 2016).

This test, likewise, includes a ninth scale concerning well-being and adjustment, called self-esteem and well-being (AUT), for the purpose of providing an assessment of the person or group assessed in positive terms. This variable constitutes one of the points of interest as it presents a negative correlation with psychopathological symptomatology (RosaAlcázar, Parada-Navas, \& Rosa-Alcázar, 2014), thereby constituting a protective factor for psychopathology.

The Q-PAD is short enough (81 items formulated in a language that is familiar according to the linguistic uses of adolescents), requiring around twenty minutes for its application. It is, equally - unlike other traditionally used instruments aimed at children and adolescents - an instrument specifically designed to assess people in this stage of development.

As for its application, it can be used both as a detection test and as screening; and its applicability includes the clinical and forensic context as part of the assessment or follow-up.

With regard to its psychometric characteristics, it is worth noting that the average of the reliability coefficients displayed by the test is .85 in relation to its internal consistency and the average value of the temporal stability coefficients is .83 .

In short, it is one of the most up-to-date tests available, specifically designed for the adolescent population, with very good psychometric guarantees; and which, of course, conveniently addresses the variables we were interested in measuring. All these questions were decisive in choosing the Q-PAD as the measuring instrument in the present study, despite the possible problems of comparability of results.

\subsection{Procedure}

Each and every one of the juveniles participated in the present study voluntari-ly, with the consent of their parents or legal guardians. In the case of the institutional-ised juveniles, the Q-PAD was incorporated in the assessment protocol applied at the time of entry into the Reform Centre. Given the reading and comprehension problems detected in some of the young people assessed, and in order to minimise possible errors that might affect the validity of the data obtained, the application of the Q-PAD was individual. This condition was, obviously, maintained in the application of the test in the group of adolescents chosen for the study belonging to the normal population, for whom informed consent was requested from their parents.

Given the limited sample size, in this study neither gender nor type of crime committed was differentiated.

\section{Results}

The direct scores obtained in each of the scales were used, based on which the means comparison tests were performed in independent groups, through the corresponding test (Palmer, 2011). In Table 1, the mean and variance is provided, for each scale and for each of the two groups. As can be observed, the mean of the group in custody is higher than the non-custody one, in all the scales except in the last one AUT.

The conditions of application of normality and homogeneity of variances were analysed (Palmer, 2011). For normality, the Shapiro-Wilk test establishes that there is no normality in the INS and FAM scales in the group in custody or in the ANS, DEP, ABU, FAM, INC and AUT scales in the non-custody group. For this reason, the non-parametric Mann-Whitney test was applied on these occasions.

The homogeneity of variances, analysed through Levene's test, provides results that indicate it is fulfilled in all the scales except in INC and ABU. On these occasions Welch's test was applied in the compliance test.

Table 2 provides, for each scale, Levene's test probability, value of the test of means difference, degree of significance, value of the difference in means between the two groups, and the $95 \%$ confidence interval of the difference in means.

Significant differences were found in the ANS, DEP, ABU, CON, INC, RPS and AUT scales, such that in the six first 
Table 1

Means and variances of the scales in each group

\begin{tabular}{llllllllll}
\hline & INS & ANS & DEP & ABU & CON & FAM & INC & RPS & AUT \\
\hline \multirow{2}{*}{ Inmates } & 13.39 & 27.75 & 19.68 & 22.57 & 19.00 & 16.41 & 19.50 & 63.02 & 35.09 \\
& $(33.92)$ & $(31.31)$ & $(29.57)$ & $(54.16)$ & $(26.70)$ & $(22.99)$ & $(48.35)$ & $(169.37)$ & $(48.09)$ \\
\multirow{2}{*}{ Non-inmates } & 12.80 & 19.69 & 12.51 & 13.51 & 15.06 & 15.83 & 15.83 & 44.49 & 38.89 \\
& $(17.22)$ & $(29.22)$ & $(19.49)$ & $(13.85)$ & $(15.59)$ & $(30.44)$ & $(48.38)$ & $(121.67)$ & $(31.63)$ \\
\hline
\end{tabular}

Note. Mean (variances).

Table 2

Comparison of means in the scales.

\begin{tabular}{llllllllll}
\hline & INS & ANS & DEP & ABU & CON & FAM & INC & RPS & AUT \\
\hline Levene's F prob & 0.04 & 0.57 & 0.18 & 0.00 & 0.11 & 0.624 & 0.99 & 0.48 & 0.20 \\
test & 0.52 & 6.46 & 6.31 & 7.09 & 3.73 & 0.50 & 2.33 & 6.72 & -2.62 \\
$p$ & .603 & $8.6 \times 10^{-9}$ & $1.8 \times 10^{-8}$ & $5.6 \times 10^{-10}$ & $3.6 \times 10^{-4}$ & .619 & 0.022 & $2.79 \times 10^{-9}$ & .011 \\
$M_{1}-M_{2}$ & 0.59 & 8.06 & 7.17 & 9.05 & 3.94 & 1.18 & 3,67 & 18.54 & -3.98 \\
$C I\left(M_{1}-M_{2}\right)$ & ns & $5.58,10.54$ & $4.96,9.375$ & $6.50,11.60$ & $1.909,5.99$ & ns & $0.532,6.811$ & $13.15,23.93$ & $-6.61,-0.98$ \\
\hline
\end{tabular}

Note. $M_{1}-M_{2}$ : Difference in means; $C I\left(M_{1}-M_{2}\right)$ : confidence interval for the difference in means.

ones, the group of inmates obtain scores greater than the noninmate ones, whereas only in the AUT scale do the inmates have a lower score than the non-inmates.

The effect size was obtained through Cohen's $d$ index in which a value of .80 in the $d$ index is considered a large effect size, whereas .50 is considered medium. Likewise, the confidence interval of the $d$ index and the Power of each test were obtained. In Table 3 , the value of the effect size, confidence interval, and the value of the statistical Power are provided for each scale. It can be observed that the scales that were non-significant in the comparison test of the two means, such as INS and FAM, are the ones that have a d index less than 0.20 (small), their confidence interval contains the value zero, and their power is also low (less than 0.10).

In the INC and AUT scales a medium effect size is obtained with a Power of $63.3 \%$ and $73.7 \%$ respectively. In the other scales (ANS, DEP, ABU, CON and RPS) large or very large effect sizes are obtained, as well as a high power, greater than $95 \%$ in all cases. It was analysed whether there is a relationship with age and each of the scales, but no significant relationship was found. Hence, age is not related to the scales. Different logistic regression models were analysed and finally the most parsimonious model was one in which only two scales are included (DEP and ABU) which enable a correct classification of $87.3 \%$ (see Table 4). The interaction between the two variables has no effect, as it is non-significant, wherefore it does not enter into the model.

In the model analysed, the Hosmer-Lemeshow goodnessof-fit test enables us to say that the model fits globally, whereas it displays a value of 0.66 in the explained percent variance of the dependent variable for the two explanatory variables in the model, Depression and Substance Abuse.

The coefficients obtained in the model make it possible to say that a 1 point rise in Depression increases the likelihood of being in the Reform Centre between $11.8 \%$ and $52 \%$ and that a 1 point rise in Substance Abuse increases the likelihood of being in the Reform Centre between $12.9 \%$ and $51.4 \%$.

Table 5 provides the frequency distribution observed in each group and the ones predicted by the logistic regression model. As can be observed in Table 5, the model presents a specificity (\% correct classification of non-inmates) of $82.9 \%$ and a sensitivity (\% correct classification of inmates) of $90.9 \%$. Finally, the total $\%$ correctly classified by the logistic regression model is $87.3 \%$.

The results obtained show that both groups studied have significant differences in all the variables included in the QPAD except for the ones that refer to body dissatisfaction and family conflicts.

Thereby, we find that the group of juvenile offenders displayed significantly higher scores in negative emotional responses (anxiety and depression), in substance abuse, interpersonal conflicts, psychosocial risk, and uncertainty about the future, as well as significantly lower self-esteem than observed in the standard group.

\section{Discussion}

According to the results obtained in the Body Dissatisfaction Scale (INS), it seems that the juvenile offenders under study do not display problems related to their body perception, their physical appearance, or to their weight. This suggests that these juveniles do not have a higher incidence of eating disorders than the young people belonging to the standard group, which is found to be in clear contradiction to what is evidenced by other studies that indicate that stress and psychosocial adversity - especially deriving from family dynamics - constitute factors that are clearly involved in the development of eating disorders (Behar \& Valdés, 2009). 
Table 3

Effect sizes and power.

\begin{tabular}{llllllllll}
\hline & INS & ANS & DEP & ABU & CON & FAM & INC & RPS & AUT \\
\hline Effect size & 0.11 & 1.46 & 1.43 & 1.50 & 0.84 & 0.11 & 0.53 & 1.52 & 0.60 \\
$C I(d)$ & $-0.33,0.56$ & $0.96,1.96$ & $0.93,1.93$ & $1.00,2.01$ & $0.38,1.31$ & $-0.33,0.56$ & $0.12,1.03$ & $1.02,2.03$ & $0.14,1.05$ \\
$1-\beta$ & 0.079 & 0.999 & 0.999 & 0.999 & 0.957 & 0.078 & 0.633 & 0.999 & 0.737 \\
\hline
\end{tabular}

Note. $\mathrm{CI}(\mathrm{d})$ : Confidence interval for $\mathrm{d}$; $1-\beta$ : power.

Table 4

Logistic Regression.

\begin{tabular}{lcc}
\hline & DEP & ABU \\
\hline$p$ & & .075 \\
$\%$ Classification & & $87.3 \%$ \\
Nagelkerke's $R^{2}$ & \multicolumn{2}{c}{0.662} \\
Exp(B) & 0.767 & 0.765 \\
CI(Exp(B)) & $0.658,0.894$ & $0.661,0.886$ \\
\hline
\end{tabular}

Table 5

Classification table.

\begin{tabular}{llll}
\hline \multicolumn{4}{c}{ Predicted } \\
\hline Observed & Non-inmate & inmate & $\%$ correct \\
\hline Non-inmate & 29 & 6 & 82.9 \\
Inmate & 4 & 40 & 90.9 \\
\hline
\end{tabular}

These differences could be explained, at least in part, by the adequacy of the context and family dynamics perceived by the group of juvenile offenders in the present study, which they assess, according to the results obtained in the FAM scale, as free of conflicts and experiences of misunderstanding that generate interferences for them in their functioning and behaviour. Nevertheless, the satisfaction with the family climate displayed by the group of juvenile offenders should not be confused with this being adequate or with the fact of the educational styles being appropriate; above all, in the knowledge that low parental involvement in the life of young people is strongly related to criminal recidivism (Barrett, Katsiyannis, \& Zhang, 2010), as well as the fact that poor parent-child interaction constitutes an important risk factor for the development of antisocial and criminal behaviour, while warm relationships would act as a protective factor (Armenta, Corral, López, Díaz, \& Peña, 2001).

Meanwhile, the results obtained on the INS scale would rule out the involvement of body self-perception in the selfesteem problems displayed in the group of juvenile offenders studied. At any rate, these results draw particular attention as low self-esteem and body dissatisfaction seem to constitute risk factors for suffering disorders related to body image (Espina, Ortego, Ochoa, Yenes, \& Alemán, 2001; Raich, 2004), while parenting styles that are perceived as positive tend to have a significant negative relationship with psychopathological symptoms (Rosa-Alcázar et al., 2014).

In this sense, the results obtained in the anxiety (ANS) and depression (DEP) scales indicate, respectively, that the group of juvenile offenders has difficulties handling the tension and worries that interfere in their everyday functioning, as well as episodes of sadness, irritability and negative feelings that might likewise make everyday life difficult. Theses results, therefore, support the idea that there is a relationship between psychopathology and criminal conduct (Fariña, Arce, \& Vázquez, 2014).

The anxious-depressive symptomatology present in the group of juvenile offenders could be due, at least in part, to uncertainty about the future (INC), a variable in which we also found significant differences between the two groups studied. According to the data obtained, the group of young offenders has worries related to their future with regard to school and employment, which is in agreement with studies such as the one conducted by Bringas et al. (2009), which reveals that this group of juveniles has greater school failure. School failure is shown to be a relevant variable in the explanation of juvenile antisocial and criminal behaviour; there has even been found a relationship between the type of skill or learning deficit and delinquency patterns in adolescents (Cruise, Evans, \& Pickens, 2011).

At any rate, it seems that poor academic performance negatively affects self-esteem and this influences the development of antisocial behaviours (Sanabria \& Uribe, 2010).

The results that point towards teenage aggressors being characterised by low self-esteem, low tolerance to frustration, and low levels of responsibility, as well as the results that indicate the existence of a significant relationship between low self-esteem and school problems, antisocial behaviour, psychopathological disorders, anxiety, and depression, are consistent with the previous literature (Arce, Velasco, Novo, \& Fariña, 2014; Álvarez García, Barreiro-Collazo, Núñez, \& Dobarro, 2016).

Finally, in relation to the social-cognitive variables that refer directly to socially inappropriate behaviours, we find that the group of juvenile offenders displays significantly higher scores than the control group in substance abuse (ABU), interpersonal conflicts (CON) and, as expected, in psychosocial risk (RPS).

In this regard, it is important to point out that the ABU scale does not measure the consumption of psychoactive sub- 
stances as much as the negative consequences experienced. Hence, it makes it possible to identify not only consumption but also the way in which this affects the daily functioning of adolescents in different contexts. Thus, the results obtained with this test reveal the lack of relationship between consumption and an effect on perceived well-being, which would be explained by the fact that the effects of substance abuse manifest themselves after years (Sica et al., 2016). Taking into account the data found in the present study, it is worth considering the hypothesis that the juvenile offenders assessed began consumption at clearly early ages. Likewise, we found results that support the idea that consumption is better explained through personal and interpersonal variables than through psychopathological variables (C. López \& Freixinós, 2001).

Meanwhile, the group of adolescent offenders displayed significantly higher scores in the interpersonal conflicts scale $(\mathrm{CON})$, which suggests, on the one hand, the existence of antisocial behaviours, marginalisation, identification with conflictive groups, problems with authority and inadequate coping strategies; and, on the other hand, distrust of others, lack of empathy, and trouble handling negative emotions. These aspects coincide with the results obtained by González-Gadea et al. (2014), which indicate that adolescent offenders display difficulties in integrating affective processes (emotion and empathy) with the contextual information from their daily life, as well as with the profile described in other studies, although there are no homogeneous data in this regard. Likewise, our results are in agreement with the work of Arce et al. (2011), who reveal the relationship between social incompetence and antisocial and criminal behaviours - which seem to be involved in the escalating effect.

Regarding the results obtained in relation to substance abuse and interpersonal conflicts (ABU and $\mathrm{CON}$ in the QPAD) and between substance abuse and anxiety and depression (ANS and DEP), it is worth noting that, on a global level $(n=79)$, a significant linear relationship is found between ABU and CON, ANS and DEP, with correlation coefficient values of $r=.406, r=0.507$ and $r=0.481$, respectively. However, when the group of non-inmates is analysed $(n=35)$, no significant relationship is found, whereas in the inmate group $(\mathrm{n}=44)$ there is a significant relationship of ABU and CON, $r=.389$, and of ABU and ANS, $r=.294$, while ABU and DEP bear no relationship ( $r=.180)$. That is, depression and substance abuse constitute the variables of greater explanatory weight for the condition of being in a situation of deprivation of liberty, although it is logical to think that precisely this condition could be the precipitating factor for the appearance and/or exacerbation of negative emotional states. An issue that would reveal, as found by Lambie and Randell (2013), the negative effects of internment and the need for possible alternative measures.

In the same way, the data indicate that in the group of juvenile offenders interpersonal conflicts and anxiety are found to be involved in substance consumption.

\section{Conclusions}

The results obtained in the present study, despite the sample size, coincide with much of the literature existing on juvenile offenders, revealing that these have different personal and social-affective characteristics than the ones observed in the standard population.

In this sense, our data would be along the same lines as the ones obtained by Leverso, Bielby, and Hoelter (2015), who found that some self-regulation deficits and pressure from parents constitute the major factors in predicting the development of a criminal career, above all in early adolescence, whereas the influence of environmental factors is variable. An issue that demystifies, at least in part, the belief that juvenile delinquency is the result of environmental conditions such as living in depressed neighbourhoods, amongst others.

The results obtained, given the differences observed between the two groups, demonstrate the need to develop validated programmes that include the assessment of psychopathological and psychosocial risk indicators which enable specific primary and secondary prevention interventions, as well as training programmes that enable adolescents to achieve an adequate adjustment to society.

Likewise, the results obtained in this study are consistent with the observations of Kennedy, Burnett, and Edmonds (2011) in indicating the involvement of personal and behavioural variables in the commission of crimes; they support the need, as they point out, for intervention programmes that promote self-esteem, tolerance towards frustration, coping with anxiety-generating situations, and coping with challenges, by guiding towards success and responsibility (Arce et al., 2014; Álvarez García et al., 2016).

Meanwhile, the coincidence between the two groups studied, regarding the family satisfaction they display, stands out. Nevertheless, by not implying that the educational styles of their parents are the most appropriate and efficient in instigating and maintaining personal and socially appropriate conduct, this suggests the need to develop studies that take into account these variables.

It is worth pointing out, likewise, that the Q-PAD seems to constitute a good assessment instrument that enormously simplifies assessment, by conveniently identifying emotional, behavioural, self-regulation and interpersonal relationship problems.

Lastly, we endorse the words of Peña and Graña (2006), who indicate that the inclusion of criteria that are not only legal in the definition of antisocial or criminal behaviour has the advantage of focusing the decision on social and personal factors, making it possible to tackle the real problem directly after appropriate assessment thereof. This way of proceeding, undoubtedly, may have a positive impact on the design and application of efficient prevention and intervention programmes, constituting one of our next goals. 


\section{References}

Alves, C., Amando, B., \& Vilariño, M. (2013). Menores infractores: Un estudio de campo de los factores de riesgo. Anuario de Psicología Jurídica, 23, 39-45.

Anderson, C., \& Bushman, B. (2002). Human aggression. Annual Review of Psychology, 53, 27-51.

Andreu-Rodríguez, J., Peña-Fernández, M., \& Loza, W. (2016). Predicting risk of violence through a selfappraisal questionnaire. European Journal of Psychology Applied to Legal Context, 8, 51-56.

Arce, R., Fariña, F., \& Vázquez, M. (2011). Grado de competencia social y comportamientos antisociales, delictivos y no delictivos en adolescentes. Revista Latinoamericana de Psicología, 43(3), 473-486.

Arce, R., Mohamed, L., Fariña, F., \& Seijo, D. (2010). Comportamiento antisocial en menores: Riesgo social y trayectoria natural de desarrollo. Revista Mexicana de Psicología, 2, 127-142.

Arce, R., Velasco, J., Novo, M., \& Fariña, F. (2014). Elaboración y validación de una escala para la evaluación del acoso escolar. Revista Iberoamericana de Psicología y Salud, 5(1), 71-104.

Archer, J. (2009). The nature of human aggression. International Journal of Law and Psychiatry, 32, 202-208.

Armenta, M., Corral, V., López, A., Díaz, S., \& Peña, E. (2001). Predictores familiares y conductuales de la problemática escolar en alumnos de secundaria y preparatoria. Revista de Psicología de la PUCP, 21, 237-256.

Barrett, D., Katsiyannis, A., \& Zhang, D. (2010). Predictors of offense severity, prosecution, incarceration, and repeat referrals for juvenile offenders: A multi-cohort replication study. Remedial and Special Education, 31, 261-275.

Behar, R., \& Valdés, W. (2009). Estrés y trastornos de la conducta alimentaria. Revista Chilena de NeuroPsiquiatría, 47(3), 178-189.

Boes, A. D., Graft, A. H., Joshi, C., chuang, N. A., Nopoulos, P., \& Anderson, S. W. (2011). Behavioral effects of congenital ventromedial prefrontal cortex malformation. BMC Neurol, 11:151.

Bringas, C., Rodríguez, F., \& Herrero, J. (2009). Responsabilidad y comportamiento antisocial del adolescente como factores asociados al rendimiento escolar. Acta Colombiana de Psicología, 12(2), 69-76.

Bringas, C., Rodríguez, F. J., Gutiérrez, E., \& Pérez, B. (2010). Socialización e historia penitenciaria. Revista Iberoamericana de Psicología y Salud, 1(1), 101-116.

Bringas, C., Rodríguez, J., López-Cepero, J., Pérez, B., \& Estrada, C. (2012). Drug abuse and criminal family records in the criminal history of prisoners. European Journal of Psychology Applied to Legal Context, 3, 89105.

Cruise, K., Evans, L., \& Pickens, I. (2011). Integrating mental health and special education needs into comprehensive service planning for juvenile offenders in long-term custody settings. Learning and Individual Differences, 21(2), 30-40.

Espina, A., Ortego, M., Ochoa, I., Yenes, F., \& Alemán, A. (2001). La imagen corporal en los trastornos alimentarios. Psicothema, 13(4), 533-538.

Fariña, F., Arce, R., \& Vázquez, M. (2014). ¿está mediada la gravedad delictiva y cronicidad de los delincuentes juveniles por la competencia cognitivo-comportamental? Universitas Psychologica, 13(3), 15-27.

González-Gadea, M., Herrera, E., Parra, M., Gómez-Méndez, P., Báez, S., Manes, F., \& Ibáñez, A. (2014). Emotion recognition and cognitive empathy deficits in adolescent offenders revealed by context-sensitive tasks. Frontiers in Human Neuroscience, 8, 1-11.

Kennedy, T., Burnett, K., \& Edmonds, W. (2011). Intellectual, behavioral, and personality correlates of violent vs. nonviolent juvenile offenders. Aggressive Behavior, 37(4), 315-325.

Lambie, I., \& Randell, I. (2013). The impact of incarceration on juvenile offenders. Clinical Psychology Review, 33(3), 448-459.

Leverso, J., Bielby, W., \& Hoelter, L. (2015). Back on the streets: Maturation and risk factors for recidivism among serious juvenile offenders. Journal of Adolescence, 41, 67-75.

López, C., \& Freixinós, M. A. (2001). Psicopatología y consumo de alcohol en adolescentes. Anales de Psicologia, 17(2), 177-188.

López, M. J., Alba, J. L., \& Garrido, V. (2007). Concreción del "superior interés del menor" en la intervención con menores en conflicto social. en f.j. rodríguez y c. becedóniz (eds.). In El menor infractor: Posicionamientos y realidades (p. 47-80). Oviedo, España: Consejería de Justicia, Seguridad Pública y Relaciones Exteriores.

Álvarez García, D., Barreiro-Collazo, A., Núñez, J. C., \& Dobarro, A. (2016). Validity and reliability of the cyber-aggression questionnaire for adolescents (cyba). European Journal of Psychology Applied to Legal Context, 8(2), 69-77.

Moral, M. V., \& Sirvent, C. (2001). Desórdenes afectivos, crisis de identidad e ideación suicida en adolescentes. International Journal of Psychology and Psychological Therapy, 11(1), 33-56.

Palmer, A. (2011). Procedimientos estadísticos con spss y $r$ para la comparación de dos medias. Palma de Mallorca: Ediciones UIB.

Peña, M. E., \& Graña, J. L. (2006). Agresión y conducta antisocial en la adolescencia: Una integración conductual. Psicopatología Clínica, Legal y Forense, 6, 9-23.

Raich, M. R. (2004). Una perspectiva desde la psicología de la salud de la imagen corporal. Avances en Psicología Latinoamericana, 22, 15-57.

Redondo, S., Martínez-Catena, A., \& Andrés-Pueyo, A. (2012). Therapeutic effects of a cognitive-behavioural treatment with juvenile offenders. European Journal of 
Psychology Applied to Legal Context, 4, 15-178.

Redondo, S., Sánchez-Meca, J., \& Garrido, V. (2002). Los programas psicológicos con delincuentes y su efectividad: La situación europea. Psicothema, 14, 164-173.

Rosa-Alcázar, A. I., Parada-Navas, J. I., \& Rosa-Alcázar, A. (2014). Síntomas psicopatológicos en adolescentes españoles: Relación con los estilos parentales percibidos y la autoestima. Anales de Psicología, 30(1), 133-142.

Rutter, M., Giller, H., \& Hagell, A. (2000). La conducta antisocial de los jóvenes. Madrid, España: Cambridge University Press.

Sanabria, A. M., \& Uribe, A. (2010). Factores psicosociales de riesgo asociados a problemáticas en jóvenes infractores y no infractores. Diversitas: Perspectivas en Psicología, 6(2), 257-274.

Sica, C., Chiri, L. R., Favilli, R., \& Marchetti, I. (2016). Qpad: Cuestionario para la evaluación de problemas en adolescentes. Madrid, España: TEA Ediciones.

Vassos, E., Collier, D. A., \& Fazel, S. (2104). Systematic meta-analysis and field synopsis of genetic association studies of violence and aggression. Molecular Psychiatry, 19, 471-177.

Z., S., Woodhams, J., \& Cooke, C. (2014). Sex differences in predictors of violent and non-violent juvenile offending. Aggressive Behavior, 40(2), 165-177. 